\title{
20 AÑOS DE ESTUDIOS PARA 600 DE RELACIONES Y CONSTANCIAS ENTRE IRÁN E HISPANIA
}

\author{
Fernando Escribano Martín \\ Universidad Autónoma de Madrid
}

\section{RESUMEN}

El objeto de esta comunicación es hacer un resumen por los momentos clave de las relaciones diplomáticas entre España e Irán, y también enumerar y hacer balance de las consecuencias bibliográficas que estas tuvieron.

Hay tres grandes momentos en estas relaciones: en el siglo XV, Enrique III de Castilla manda una embajada al Tamorlán encabezada por González de Clavijo, que de algún modo es un precedente de las embajadas posteriores a Irán. En el siglo XVII se produjo un intercambio diplomático entre ambos países que quizá no obtuvieron el objetivo político y militar previsto, pero sí una producción de textos absolutamente única $y$ de una calidad altísima. Por último, una especie de rara avis, en el siglo XIX, la aventura diplomática de Adolfo Rivadeneyra en Irán dio como consecuencia un libro singular: Viaje al interior de Persia, como consecuencia de un año y medio de viajes y estudios por el país.

Los contactos entre España e Irán han tenido siempre consecuencias bibliográficas sorprendentes, igual que lo son su estudio, novedad y sorpresas que siguen deparando.

\section{PALABRAS CLAVE}

Irán, Monarquía Hispánica, Viajeros, Rivadeneyra, García de Silva, Bibliofilia.

\begin{abstract}
The purpose of this communication is to summarize the key moments of diplomatic relations between Spain and Iran, and also enumerate and take stock of the bibliographic consequences they had.

There are three great moments in these relationships: in the fifteenth century, Enrique III de Castilla sent an embassy to Tamorlán headed by González de Clavijo, which is somehow a precedent for later embassies to Iran. In the seventeenth century there was a diplomatic exchange between both countries that perhaps did not achieve the intended political and military objective, but yes an absolutely unique production of texts of a very high quality. Finally, a kind of rare avis, in the nineteenth century, the diplomatic adventure of Adolfo Rivadeneyra in Iran resulted in a unique book: Travel to the interior of Persia, as a result of a year and a half of travel and studies in the country.
\end{abstract}

The contacts between Spain and Iran have always had surprising bibliographical consequences, as are their study, novelty and surprises that continue to hold.

\section{KEYWORDS}

Iran, Hispanic Monarchy, Travelers, Rivadeneyra, García de Silva, Bibliophilia.

En su libro Viaje al interior de Persial ${ }^{1}$, Adolfo Rivadeneyra hace una incursión por los contactos previos que habían existido entre España e Irán. Partiendo de la información de un legajo del archivo del Palacio Real y lo que él "tenía aprendido de nuestra historia general" va haciendo un repaso histórico de estos contactos. Así, habla de unos persas que se asentaron en Loja en tiempos de Alfonso el Católico (Alfonso I de Asturias, 739-759

1 1880, en tres tomos, Madrid, Imprenta y Estereotipia de Aribay y Ca . (sucesores de Rivadenerya). Hay también una edición no íntegra, por parte del autor de este artículo, publicada en la Editorial Miraguano, Madrid, 2008. Esta segunda edición se tradujo al farsi, por la profesora Maryam Hagroosta, en Teherán en 2018. Para este repaso de los contactos diplomáticos previos establecidos entre Irán y España: 1880, tomo I, pp. 2-14. 2008, pp. 97-108. 
d.C.), o de la expedición comandada por Pedro Solivera² ${ }^{2}$ de parte de Jaime II de Aragón a Gazán, rey de Persia, con cartas e instrucciones de fecha 18 de mayo de 1300, sin que consten ulteriores relaciones.

Habla después de la embajada que envió Enrique III el Doliente, rey de Castilla, al gran Tamerlán, consecuencia de la que le envió el señor de Samarcanda tras la presencia de otros dos embajadores, Payo Gómez de Sotomayor y Hernan Sánchez Palazuelos en la batalla de Ankara que supuso la derrota del Sultán Bayaceto. La embajada, encabezada por Rui González de Clavijo está perfectamente descrita por el texto que escribió el embajador, la Embajada a Tamorlán, cuyo mejor editor y estudioso es sin duda Francisco López Estrada $^{3}$. Este texto, como otros que vamos a repasar en esta comunicación, tiene también historia propia, y viene citado cada vez que se hace una recopilación o un estudio sobre la historia de los contactos iranio-hispánicos. Así se produce, por ejemplo, en el Discurso sobre el itinerario de Ruy González de Clavijo que escribe Argote de Molina en su Historia del gran Tamorlán (Sevilla, Andrea Pescioni, 1582). Se puede pensar que la recuperación de este texto, "bajo el amparo de Antonio López", fue casual, o debida solo a intereses bibliófilos, pero el precedente de las embajadas del siglo XVII está en los contactos que ya se mantuvieron en tiempos de Carlos I y Felipe II, y por lo tanto, esta recuperación de textos, como la producción de otros, se da en momentos de intensificación de los contactos, cuando vuelve a ser interesante hablar o recuperar un tema. En el mundo editorial, como en el político, las casualidades son escasas. Esta proliferación de textos en el siglo XVII, en torno a viajes a Irán o su historia, contemporáneos o recuperados, está en relación con los contactos políticos que se estaban estableciendo.

Comienza Rivadeneyra el repaso a las embajadas que se produjeron en el siglo XVII con las figuras de los hermanos Anthony y Robert Sherley. Las figuras de estos dos católicos británicos son más que comprometidas a la hora de valorar su importancia real en la gestación de las misiones en las que participaron, pero lo cierto es que dirigieron o codirigieron embajadas del shah Abbas I el Grande a las cortes europeas. Sir Anthony, a partir de un momento, pasó a ser un personaje molesto en la corte hispánica $\mathrm{y}$, seguramente más temido que respetado por el aura que le rodeaba, además de muchas propuestas más o menos inverosímiles que elevaba al rey, escribió un tratado de geopolítica contemporánea que reflejaba su saber de primera mano sobre El estado del mundo ${ }^{4}$ de su tiempo.

Siguiendo a Rivadeneyra, a la primera embajada del shah encabezada (no se pusieron nunca de acuerdo en quién era el embajador) por Anthony Sherley y Uzen Alí Bey, respondió Felipe III con otra formada por fray Antonio de Gobea, fray Jerónimo de la Cruz y fray Cristóbal del Espíritu Santo, que tuvieron audiencia con el shah, en Maged, el 4 de septiembre de 1602. De vuelta, el shah envió otra embajada con Maculí Bey Bauticaré, Alí Guli Bey, Boniat Bey y Orush Bey. Aunque aquí hay alguna mezcla de años y datos, pues la embajada donde las tres últimas personas señalados se convirtieron al cristianismo pertenecen a esa primera embajada. Uno de los tres conversos, con el nuevo nombre de Juan de Persia, escribió otro texto fundamental fruto de estos intercambios que vamos a comentar más adelante. Envió después el shah en 1610 a Robert Sherley y

\footnotetext{
2 Rivadeneyra, 1880 , tomo I, p.3.

3 Ver por ejemplo su edición en Castalia, Madrid, 1999. Y del mismo modo, dentro de la ingente labor llevada a cabo por Miraguano Ediciones en la recuperación de textos más o menos olvidados de viajeros a Oriente, ver la Embajada a Tamerlán, publicada en la colección Libros de los Malos Tiempos, a partir de la edición de Argote de Molina, también en 1999. Esta edición incluía un cuadernillo introductorio firmado por Ramón Alba. Ver también el artículo en Arbor 711-712: "Ruy González de Clavijo. La embajada a Tamorlán. Relato del viaje hasta Samarcanda y regreso (1403-1406"), de F. López Estrada.

4 Akal saca todos los años un libro con este título, con los datos básicos de todos los países, y análisis de distinto tipo por países, regiones y temas. En parte, con todas las distancias, se puede asimilar a lo que hizo Anthony Sherley, su Peso político de todo el mundo.
} 
Danguiz Bey como embajadores para apremiar en los preparativos para la guerra contra el Turco. Apunta después Rivadeneyra la embajada de Fray Antonio de Gobea, obispo de Sirene, en 1612, señalada en la Vida del Gran Tamorlán, sacada de los Comentarios de Don García de Silva y Figueroa, y su posterior misión, retrasada hasta 1618, que coincidió con una segunda de Robert Sherley en sentido contrario.

La gran embajada, por su importancia, pero sobre todo por el texto que escribió el embajador, es la de García de Silva y Figueroa. Rivadeneyra habla de que desgraciadamente el texto no ha llegado completo hasta nosotros (1880, T. I, p.13), señala la edición de Wicqfort de 1667 (que no responde al manuscrito original sino a una copia a la que le faltan algunos libros) mientras el texto castellano permanece inédito hasta tanto que la suerte le depare un editor, como se lo deparó a la obra de Clavijo (1880, T.I, p. 13).

Termina esta introducción con una mención al Manifiesto de los Persas, y al establecimiento de relaciones firmado en Londres en 1842 entre España e Irán, ratificado en 1872, y que están en el origen de su misión. No me queda claro, por la redacción, si Rivadeneyra conocía a esas alturas la intención o posibilidad de edición de este manuscrito que se llevó a cabo en 1903, de la mano de Manuel Serrano y Sanz con la Sociedad de Bibliófilos Españoles, a partir de los manuscritos rescatados por Pascual de Gayangos y Arce, que es también una aventura en sí, de la que poco nos vamos a ocupar más adelante. Pero sí queda claro el conocimiento que se tenía en su época sobre los contactos históricos entre España e Irán, y que él quiso glosar a la hora de introducir su misión y la documentación con la que la preparó.

\section{Sobre el siglo XIX}

En el siglo XIX, en España, y desde distintos ámbitos, hubo estudiosos y gestores, ocupados más o menos directamente en la cultura y en la investigación, o que intentaron favorecerla, que pretendían sacar a la ciencia española de cánones antiguos y situarla en estándares europeos. Hemos citado ya a Pascual de Gayangos y Arce ${ }^{5}$, cuyo trabajo en el desarrollo de un cuerpo de archiveros y bibliotecarios profesionales que hasta entonces no existía, su sistematización y catalogación de los documentos en español del British Museum, su vinculación con historiadores americanos y británicos con los que trabajó, o su colaboración con revistas científicas de distintos países, sobre todo británicas, le hubiesen significado ya una mención merecida en este repaso por investigadores y viajeros a Oriente, o más exactamente a Irán. Pero es que su pasión de bibliófilo le hizo atesorar una fabulosa biblioteca y archivo que hoy son el orgullo de la Biblioteca Nacional y de la Academia de la Historia. Entre los textos que rescató del olvido o directamente de la destrucción, está el manuscrito original de los Comentarios de García de Silva sobre su embajada a Persia y de la copia parcial contemporánea que, no sabemos por qué ni cómo, trascendió más que el manuscrito primero. La historia de estos dos manuscritos, que se debían conocer en círculos restringidos, todavía no está clara, pero el papel clave de Gayangos en su salvación y posterior edición ${ }^{6}$, no deja lugar a ninguna duda.

\footnotetext{
5 Ver "El extraño exilio de Pascual de Gayangos en Londres", de 2011, capítulo de F. Escribano dentro de un libro sobre el exilio liberal londinense. Aunque para entender bien el trabajo, las pretensiones, las fuentes y el éxito de Gayangos, hay que leer la obra de Santiño: Pascual de Gayangos. Erudición y cosmopolitismo en la España del XIX, además de otros trabajos ya clásicos sobre el gran bibliófilo, y que aparecen citados en los dos estudios.

6 Esta primera edición fue llevada a cabo por Manuel Serrano y Sanz junto a la Sociedad de Bibliófilos Españoles. Posteriormente, este texto ha sido editado (en español) y estudiado ampliamente por el equipo encabezado por Rui Loureiro, del Centro de Historia de Além-Mar, de la Universidade dos Açores. Hay también una reciente edición en inglés, con una interesante introducción: Turley, T.S. \& Souza, G. B., 2017, The Commentaries of D. Garcia de Silva y Figueroa on his Embassy to Shah Abbäs I of Persia on Behalf of Philip III, King of Spain.
} 
En los inicios del Orientalismo como ciencia, los pioneros fueron diplomáticos y estudiosos de distintos ámbitos, y lo mismo podría decirse de España, aunque la trascendencia no fuese después la misma en cuanto a la institucionalización de la ciencia ${ }^{7}$.

Anibal Rinaldi, superior de Rivadeneyra en Beirut, envió a la reina unas Reflexiones acerca del idioma árabe que mostraban el progreso del joven de lenguas en este idioma, y que luego este incluyó en el primero de sus libros ${ }^{8}$. Rinaldi fue no sólo un brillante intérprete desde joven ${ }^{9}$ sino que apreció o propició trabajos de distinto tipo en el desempeño de sus funciones. Antonio Bernal de O'Reilly es otro ejemplo de diplomático fascinado por el Oriente y que realiza y publica sus propios trabajos: En el Libano: cartas relaciones sobre la Siria (1888); Jerusalén: la Semana Santa: apuntes histórico-religiosos (1877); Elementos para el ejercicio de la carrera consular (1883) o Viaje a Oriente: en Egipto (1876), entre otras publicaciones. Eduardo Saavedra y Moragas (1829-1912, político, ingeniero, arquitecto, arqueólogo y arabista) es otro magnífico ejemplo de todo lo que se hizo en el siglo XIX en España en relación al Oriente, y de las prometedoras bases que se asentaron en el desarrollo científico que se pretendía. Baste como ejemplo de lo dicho lo que publicó: "Descripción de la vía romana entre Uxama y Augustóbriga", en Memorias de la Real Academia de la Historia, vol. 9, 1879; La Geografía de España de El Idrisí (1881); Intereses de España en Marruecos (1884); Estudio sobre la invasión de los árabes en España (1891) y La mujer mozárabe (1904). Acompañó o convocó a Rivadeneyra a la inauguración del Canal de $\mathrm{Suez}^{10}$, y fue el que firmó y leyó su elogio fúnebre.

Creo que, además de Rivadeneyra, junto a todos estos magníficos intelectuales que lucharon en pro del Orientalismo y sobre todo de la ciencia en general, desde un punto de vista académico, destaca la figura de Francisco García Ayuso ${ }^{11}$. Nació en Valverde del Majano, Segovia, en 1835, y murió en Madrid en 1897. Fue académico de la Real Academia Española, profesor auxiliar de la Universidad Central y catedrático del Instituto San Isidro de Madrid. Fue sin duda el mayor especialista español del momento en sánscrito y zend, además de dominar otras lenguas como el etíope, siriaco, turco, árabe, persa, hebreo, latín, griego, alemán, francés, inglés... de todas ellas, hasta diecinueve, daba clases en su Academia de Lenguas, y también de acadio. Sí, en el Madrid de 1874 se daban clases de acadio, y es él quien traduce, transcribe y hace una introducción a la escritura cuneiforme ${ }^{12}$ del ladrillo que Rivadeneyra tomó de Babilonia y que hoy está en el Museo Arqueológico Nacional. Gracias a su dominio de las lenguas, traduce y edita multitud de trabajos sobre

\footnotetext{
7 Las figuras de Adolfo Rivadeneyra o la de Francisco García Ayuso corren paralelas a las de los pioneros europeos del Orientalismo, pero su trabajo no tuvo aparente continuidad, y fueron objeto, posteriormente, de un redescubrimiento sorprendente. Sobre la historia del Orientalismo en España: Córdoba Zoilo, J.M., Jiménez Zamudio, R. y Sevilla Cueva, C. (editores), Actas del Primer Seminario Monográfico de Primavera, El Redescubrimiento de Oriente Próximo y Egipto. Viajes, hallazgos e investigaciones, Supplementa ad Isimu. Centro Superior de Estudios de Asiriología y Egiptología. UAM. Ver también: Molinero Polo, M.A., "La creación frustrada de cátedras de lenguas orientales (egipcio antiguo, asirio y chino) en la Universidad Central”, Gerión, 2011, 29, núm 2., pp. 15-33; Vidal Palomino, J. (2017-18), "Max-Luis Aldrey Pereira, pionero de la Asiriología en España" en ISIMU 20-21, Córdoba Zoilo y Del Cerro, C. (coords.), Amanece por Oriente, cae la niebla... Homenaje a Karlheinz Kessler, pp. 147-161, y García Recio, J., "R. Fernández Valbuena: el despuntar de la Asiología", en el volumen editado por Córdoba, Jiménez y Sevilla, 2001, pp. 117-128.

8 Viaje de Ceylán a Damasco. Golfo Pérsico, Mesopotamia, Ruinas de Babilonia, Nínive y Palmira, y Cartas sobre la Siria y la Isla de Ceilán (1871), Viaje de Ceilán a Damasco (2006).

9 En esta faceta aparece en el Aita Tettauen, uno de los Episodios Nacionales de Pérez Galdós.

10 F Escribano Martín, 2015-16, “Aida, el Canal de Suez y su inauguración. Ópera en tres actos, epílogo y adenda".

11 F. Escribano Martín, 2001, "Los estudios sobre Oriente en la España de finales del siglo XIX: la vida y la obra de Francisco García Ayuso".

12 Forma parte de su capítulo Las ruinas de Babilonia del Viaje de Ceilán a Damasco. 2006, pp. 116-117.
} 
Oriente y sobre todo sobre la cultura india, además de realizar gramáticas para varios idiomas o producir trabajos de recopilación y análisis en base a fuentes que muy pocos manejaban en España. Fundó y desarrolló una Biblioteca Sanskrita y dentro de sus Estudios sobre el Oriente podríamos destacar Los pueblos Iranios y Zoroastro ${ }^{13}$ (1874) e Irán o del Indo al Tigris. Descripción geográfica de los países iranios, Afghanistán, Beluschistán, Persia y Armenia (Madrid, París, 1876). Sus libros son muchos, y se señala una selección en nota a pie de página ${ }^{14}$. Entre ellos se puede destacar el realizado sobre Afganistán ${ }^{15}$, continuación y ampliación del anterior, y que fue objeto de una edición recientemente. Como se recoge en la introducción de la edición moderna, sigue sorprendiendo que su estudio continúe sirviendo para entender el país actualmente.

Este es el contexto del siglo XIX, con la creación de la Sociedad Geográfica de Madrid $^{16}$, o la participación activa de alguno de estos personajes en distintos congresos internacionales que están en el origen del Orientalismo y de la exploración geográfica científica. Y es en este contexto donde surge la figura de Adolfo Rivadeneyra, del que hablaremos tras recorrer los tres tiempos de relaciones entre España e Irán que ya han sido introducidos.

\section{La embajada al Tamorlán. El primer libro de viajes europeo}

No está claro el sentido de la presencia de dos nobles castellanos, Payo de Sotomayor y Fernando de Palazuelo en la batalla de Angora (Ankara, 20 de julio de 1402), si iban a visitar al sultán turco derrotado, Bayaceto, o a Tamerlán. Lo cierto es que fueron recibidos por el vencedor, Tamerlán, y devueltos a tierras castellanas con la embajada correspondiente.

Enrique III envió otra embajada como respuesta, con regalos acordes a la importancia del señor de Samarkanda, presidida por su camarero, el madrileño Ruy González de Clavijo, con Gómez de Salazar, que murió en Nishapur y el maestro de teología fray Alonso Páez de Santa María. Partieron del Puerto de Santa María el 26 de julio de 1404, consiguieron entrevistarse con el gran Tamorlán en septiembre, fueron agasajados y permanecieron en su corte dos meses y medio, para volver a la península el 1 de marzo de 1406. Ruy González de Clavijo tuvo casa cerca de lo que hoy sería la Plaza de la Paja, en Madrid, y fue enterrado en San Francisco, aunque su magnífico sepulcro fue después desmontado para hacer hueco al de una reina.

El relato sobre la embajada "se redactaría en la corte de Enrique III poco después de la llegada de los embajadores en $1406^{17 "}$, y es más que probable que hubiese una intención previa de montar este relato y a la expedición le acompañase un escribano. La costumbre

\footnotetext{
13 El encuentro casual de este libro en una librería de viejo por parte del Profesor Córdoba supuso un redescubrimiento de este gran estudioso.

14 Francisco García Ayuso. Ensayo crítico de Gramática comparada de los idiomas indoeuropeos sanskrit, zend, latín, griego, antiguo eslavo, litáuico, godo, antiguo alemán y armenio (1877-79; 2. ${ }^{\circ}$ ed. 1886). El estudio de la Filología en su relación con sanskrit, Madrid: 1871, Imprenta estereotipia de M. Rivadeneyra. Cabos sueltos de historia ó hechos importantes de la historia y de las tradiciones de los pueblos: examinados á la luz de los descubrimientos modernos, Madrid: Sucesores de Rivadeneyra, 1876. Los descubrimientos geográficos modernos, Madrid: 1877, Establecimiento Tip. de M. Minuesa de los Ríos. Discursos leídos ante la Real Academia Española, Madrid: 1894, Sucesores de Rivadeneyra. Viaje de Rohlfs de Trípoli a Lagos, á través del desierto del Sahara (Madrid, 1878). El Nirvana Budista en sus relaciones con otros sistemas filosóficos (1885). Viajes de Livingstone al Africa central desde 1840-73 (Madrid, 1876).

15 El Afghanistan: descripción histórico-geográfica del país, religión, usos y costumbres de sus habitantes: redactado con sujeción a las relaciones de viajeros contemporáneos, Madrid: 1878, Est. Tip. de R. Labajos. Edición íntegra en Miraguano Ediciones, Madrid: 2011, realizada por Fernando Escribano Martín.

16 Rodríguez Esteban, José Antonio, 1996, Geografía y colonialismo. La Sociedad Geográfica de Madrid (1876-1936). Madrid, UAM Ediciones.

17 Ruy González de Clavijo. Embajada a Tamorlán. Edición de Francisco López Estrada de 1999, p. 53.
} 
de atribuirle el texto al embajador es solo una posibilidad ${ }^{18}$, no hay nada que lo demuestre plenamente, pero se ha quedado ya asentada.

El texto ha tenido varias ediciones y traducciones, alguna de las cuales coincide con momentos de interés o aproximación desde Occidente a tierras iranias. Así, la primera, la de Argote de Molina (1582): Historia del Gran Tamorlán e Itinerario y Enarración del viaje, y relación de la Embaxada que Ruy González de Clavijo le hizo por mandado del muy poderoso Señor Rey Don Henrique el Tercero de Castilla ... fue conocida y apreciada en su tiempo. La segunda edición es la que llevó a cabo Sancha, en 1782, que incluye sobre la vida del Tamorlán información sacada de los Comentarios de García de Silva y Figueroa. Esta edición se difundió mucho más, y se suele encontrar en un tomo de nombre "Crónica de los Reyes de Castilla" junto a la Crónica de don Pero Niño, conde de Buelna, de Gutierre Díaz de Games y el Sumario de los Reyes de España, con numeración independiente ${ }^{19}$.

Las traducciones del texto que se llevaron a cabo en el siglo XIX al ruso $\left(1881^{20} \mathrm{y}\right.$ luego 1928) y al inglés (1859²1, 1971 y 1990) deben ser puestas en relación al Gran Juego desarrollado en la zona hasta la caída del Imperio turco tras la Primera Guerra Mundial. Además, y sin pretender señalar todas las traducciones, fue también vertido al persa en 1958, al francés en 1990 y hay una edición al turco sin fechar. En las ediciones en español, hay que señalar la de 1943 del CSIC, obra ya de López Estrada, su gran estudioso, una antología de la embajada, publicada en Buenos Aires en 1952 de la mano del mismo investigador, la de Miraguano de 1999, realizada a partir del texto de Sancha, con el cuadernillo de introducción a cargo de Ramón Alba, además de la también señalada de 1999 en Castalia. Estas dos últimas son las que estamos utilizando.

Se puede pensar de este texto que es el primer libro de viajes europeo desde un punto de vista cultural ${ }^{22}$, y desde luego quedó siempre como referencia y precedente de los posteriores viajes que desde Hispania se dieron a tierras iranias, tres veces cada dos siglos, y con un pico de embajadas y textos que emanaron de ellas en el siglo XVII.

\section{Embajadas y textos entre Hispania e Irán en el siglo XVII}

En 1523 el shah Isma'il I (1501-1524) envió una carta a Carlos V y al rey de Hungría Luis II (derrotado y muerto en la batalla de Mohacs en 1526 a manos turcas), y en 1529 el emperador le envió otra proponiéndole una alianza contra el Turco ${ }^{23}$.

En el Archivo General de Simancas hay una copia de una carta que el emperador Maximiliano II le envió al shah Tahmasp de Persia ${ }^{24}$, con conocimiento y consultas a Felipe II, y quizá solo conocimiento pero posterior participación e iniciativa propia por parte del rey don Sebastián de Portugal, en la que se planteaba una alianza contra el sultán turco. Tiene fecha de 8 de marzo de $1556^{25}$.

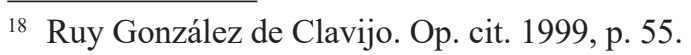

19 Ruy González de Clavijo. Op. cit. 1999, p. 55.

20 Sreznevski, Izmail Ivanovic. Ruy Gonzales de Clavijo, Itinéraire de l'Ambassade Espagnole á Samarcande en 1403-1406. St Pétersbourg. Doble portada, rusa y francesa.

${ }^{21}$ Markham, Clements R (introducción y notas). Life and acts of the Great Tamerlane: narrative of the Castilian Embassy of Roy Gonsales de Clavijo, 1403-1406. Londres, Hakluyt Society,.

22 No estamos incluyendo las rihlas, algunas de las cuales, y muy significativas, se dieron desde Al-Andalus.

${ }^{23}$ Córdoba Zoilo, 2011-2012, pp. 167-168, cita a R. Savory: Irán and the Safavids. Cambridge University

Press, Cambridge, 1980, p. 108.

24 Gil Fernández, 2006, tomo I, pp. 57-58.

25 AGS E385, fs. 58, 54, 59.
} 
Antes de las embajadas que vamos a comentar a continuación, por lo tanto, se sucedieron otras previas con el mismo sentido político de la alianza contra el Turco ${ }^{26}$ entre el shah de Persia y las cortes europeas, promovidas sobre todo desde las cortes de la casa de Austria y el papado, o al menos así nos costa según la documentación consultada ${ }^{27}$. La iniciativa que se dio desde la cancillería irania la solemos tratar menos.

La importancia del papel de Anthony Sherley en la decisión que tomó el sah Abbas I de retomar los contactos con las cortes europeas que hemos citado previamente para atacar al Turco en dos frentes se puede magnificar más o menos, pero no cabe duda que llegó en el momento oportuno ${ }^{28}$, cuando el shah barajaba ya esa posibilidad como consecuencia de varios acontecimientos concatenados, independientemente del rol que se atribuyó el católico inglés de mediador y cercanía con los reyes europeos.

Si seguimos el discurso del inglés ${ }^{29}$, él fue el protagonista y él le decía al shah lo que había que hacer, pero bien es sabido que con las memorias y con los textos laudatorios, propios y extraños, más o menos obvios, el historiador debe mantener las distancias precisas.

Se organizó una embajada con cartas a las principales cortes europeas que estaría formada por entre veinte y veinticinco personas. Nunca quedó claro, o así se ve desde quien escribió al respecto desde Occidente, si Husein Ali Beg o Anthony Sherley estaban al mando. Iban también en la embajada fray Nicolás de Melo, que se había arrogado un papel, no era el único, de embajador del papa y del rey hispánico, fray Alfonso Cordero y cuatro caballeros persas (Uruch Beg / Juan de Persia; Azán Alí Beg; Alí Quli Beg y Boniat Beg), de los cuales solo uno regresaría a Persia. Señalamos el nombre que tomó al cristianizarse el primero de ellos, pues suyos son unas Relaciones, otra de las consecuencias bibliográficas importantes de estas embajadas, de las que hablaremos más tarde.

Eligieron la ruta de Tartaria y Moscovia, y el persa portaba cartas del shah para el gran duque de Moscovia, el rey de Polonia, el emperador de Alemania, la reina de Inglaterra, el rey de Escocia, el rey de Francia, la señoría de Venecia, el rey de España y el papa ${ }^{30}$.

La embajada transcurrió por Moscú (diciembre de 1599), Praga (octubre de 1600) y Florencia (marzo de 1601). Ya desde la ciudad del Arno la convivencia entre los dos embajadores es imposible. El papa, que se entrevista con ambos por separado, separó en Roma la comitiva. A mediados de julio de 1601 Husein Ali Beg está en la Península Ibérica: Valladolid, 13 de agosto de 1601 y Lisboa, 8 de noviembre de 1601.

De las aventuras y desventuras de esta parte de la embajada original, de las que tantos se fueron cayendo y que regresó muy mermada a Irán, poco vamos a hablar, pero sin duda, desde el punto de vista de la bibliografía que emanó de estas embajadas, el gran protagonista es Uruch Beg, que se cristianizó con el nombre de Juan de Persia, y que

\footnotetext{
${ }^{26}$ Sobre literatura escrita en torno al Imperio otomano en el siglo XVI desde la Monarquía hispánica, con las dudas que hay sobre la autoría, es muy interesante el texto del humanista Cristobal de Villalón (¿15051581?), Viaje a Turquía, donde narra, en forma de diálogo, un periplo vital en territorio enemigo.

27 No es baladí esta apreciación. Estamos trabajando sobre todo con documentación del Archivo General de Simancas. No es extraño pensar en la posibilidad de otras embajadas a/o desde otras cancillerías europeas, con el mismo destino: Irán.

${ }_{28}$ Gil, 2006, tomo I, pp. 79 y 80: refleja un breve del papa, de 1592, instándolo a unirse a la guerra entre el Sacro Romano Imperio y la Sublime Puerta que se dio en 1593. Señala también como fundamental el levantamiento de Simeón de Kartli, príncipe georgiano, frente al sultán, o la propia llegada de los hermanos Sherley y fray Nicolás de Melo a Persia para la decisión de desencadenar el envío de la embajada iraní a las cortes europeas.

29 His Relation of his Travels into e interior of Persia. Ver también: E.D. Ross (ed.), Sir Anthony Sherley and his Persian adventure. Including some contemporary narratives relating thereto, London, 1933.

30 Gil Fernández, 2006, tomo I, pp. 86-88.
} 
escribió un texto absolutamente fundamental para conocer el trayecto y las vicisitudes de la embajada desde dentro, y que sería uno de los primeros textos en occidente, en el que un autor iraní narrase la historia de su país. En marzo de 1602 parte para Irán el embajador Husein Alí Beg y, en carta con fecha 24 de diciembre de 1602, comunica haber despachado con el shah acerca de la embajada y del propósito que la había provocado.

De la embajada señalada y del papel de Anthony Sherley en la corte hispánica se puede hablar largo y tendido, pero aquí vamos a recordar solo uno de sus textos, fundamental para tener una visión global de la política mundial del siglo XVII: El peso político de todo el mundo, un análisis geopolítico universal para este siglo, que se podría complementar con el Discurso sobre el aumento de esta monarquía, analizando la hispánica ${ }^{31}$. Independientemente de los anhelos de grandeza del personaje, y de cómo pretendiese utilizar estos textos, lo cierto es que los escribe, quien había conseguido convencer a varias cancillerías de su valía y trascendencia en distintas misiones, quien había combatido en distintos bandos, quien había recorrido el mundo como embajador, político o buscavidas, por tanto, también por temido, algo sabía.

Después de esta, hubo otras embajadas entre las cortes irania e hispánica, con mayor o menor fortuna y repercusión en sus intenciones, pero la más importante, sobre todo por el magnífico texto que emana de ella, es la dirigida por García de Silva y Figueroa, enviada de parte de Felipe III al shah Abbas I el grande.

\section{La embajada y los Comentarios de don García de Silva y Figueroa}

Tras varias embajadas menores, por fin se decide la figura del embajador, los regalos que llevar al shah, e incluso el pago a nuestro protagonista, que será García de Silva y Figueroa, natural de Zafra. Será la suya una misión larga y entorpecida por la administración portuguesa, que veía en él a un extranjero y sobre todo a un enviado del rey que podía poner en evidencia las corruptelas y ineficacias del gobierno de ese territorio. De ahí lo prolongado de la misión, casi siempre parada a la espera de un permiso o de un barco que pocas veces no llegó por causas naturales. Y sin embargo, la embajada tuvo como resultado un texto magnífico que permaneció casi desconocido durante mucho tiempo.

El 8 de abril de 1614 parte de Lisboa la flota que porta a la embajada a tierras iranias. Tras múltiples retrasos e impedimentos consiguen llegar a Ormuz el 29 de abril de 1616 y están en Irán el 12 de octubre. El 5 de abril de 1618, nuestro embajador sale de Shiraz camino de Isfahan, donde entró el 1 de mayo.

El texto que escribe Silva personalmente, sus Comentarios, son un compendio de ciencia naútica, observaciones históricas, naturalísticas y antropológicas. También es un relato que narra el viaje, y tiene varios hitos absolutamente claves para la ciencia, de los cuales vamos a señalar dos. De camino a Isfahan visitó las ruinas de Chilminara, que relacionó sin duda con Persépolis. No solo describió con profusión de detalles las ruinas, los edificios, los elementos arquitectónicos o los relieves, también mandó pintar alguno de ellos, y estas ilustraciones forman parte del manuscrito. Siendo estas imágenes las primeras no fantasiosas hechas sobre las ruinas ${ }^{32}$. Del mismo modo, y también en Persépolis, identifica como tal la escritura cuneiforme, de la que también manda hacer una copia, y no como un mero elemento decorativo. Solo estas dos aportaciones le deberían valer un puesto destacado en la historia del Orientalismo, pero sin embargo apenas se le conoce, o se cita a su coetáneo Andrea della Valle como un antecedente, cuando el verdadero precursor fue el embajador castellano, que sería el que con más conocimiento y con una cierta anterioridad trató estos temas.

${ }^{31}$ Existe una edición de ambos textos, en Ediciones Polifemo, de 2010, a cargo de Ángel Alloza Aparicio, Miguel Ángel de Bunes y José Antonio Rodríguez Torres.

${ }^{32}$ Córdoba Zoilo, 2011-2012, p. 202. 
El embajador dejó Isfahan el 25 de agosto de 1619 tras entrevistarse con el shah, con el que no llegó a acuerdos concretos. Solo el 28 de enero de 1624, desde la India, pudo embarcarse hacia España. Murió el 22 de julio de 1624 en el mar, cuando había pasado el Cabo de Buena Esperanza.

La embajada que encabezaba García de Silva es una aventura maravillosa que no tuvo resultados políticos, pero sí un texto único que tiene una historia propia. Embajadas como esta, más o menos importantes, más o menos trascendentes, hubo muchas, también en este tiempo y entre estos espacios geográficos, pero es el hecho de que se escribiese sobre ellas, normalmente por sus protagonistas, los que las hacen diferentes, como es el caso.

El embajador murió antes de llegar a Lisboa, en 1624, pero el texto se conservó, se hizo al menos una copia parcial y sería conocido por unos pocos. En 1667, Wicqfort realiza una edición del manuscrito en francés, copia de la copia del original, al que le faltan varios libros. Recordemos también que la edición de Sancha recoge una vida de Tamorlán a partir de los Comentarios de don García. En el siglo XIX, Pascual de Gayangos recupera los dos manuscritos, que hoy se conservan en la Biblioteca Nacional, de una librería de viejo, y es obvio que está involucrado en la primera edición íntegra que se lleva a cabo por la Sociedad de Bibliófilos Españoles de la mano de Manuel Serrano y Sanz en 1903 y 1905, en dos tomos. Hay que esperar hasta 2017 para tener una edición íntegra, traducida al inglés del texto ${ }^{33}$, con un buen aparato crítico, y antes, en 2011, aparece la magnífica edición llevada a cabo por Rui Manuel Loureiro ${ }^{34}$, Ana Cristina Costa Gomes \& Vasco Resende del texto en castellano.

Se puede entender la poca trascendencia que en la historia de la ciencia ha tenido un texto que se merece mucho más. Hay un episodio que estudia Córdoba ${ }^{35}$, el encuentro y enfrentamiento entre nuestro protagonista y Pietro della Valle en la corte safaví, y que habla del distinto destino que sufrieron la memoria y las obras de estos dos viajeros a Irán. Por una parte, el olvido, aunque ahora se recupere su memoria, del embajador castellano, por otra la subida a los altares de la fama del peregrino romano, pero esa es una historia que está muy bien contada en el texto del catedrático de Historia del Oriente Próximo, y de la que huelga decir nada más aquí.

Hemos ya hablado del texto de don Juan de Persia, Uruch Bech, que fue también consecuencia, quizá indirecta, de una de estas embajadas del XVII de las que estamos hablando. Las Relaciones de Don Juan de Persia fueron publicadas en 1604 en Valladolid. El libro, tal y como se señala en el título, tendría tres partes: una descripción de hechos y circunstancias, también curiosidades, de Irán; una historia del país y una narración del viaje de la embajada, que les lleva desde Irán a España, y que el autor considera del nivel de los periplos de Marco Polo o Cristobal Colón. Ciertamente es un viaje excepcional, pero repetido en parte en el siglo XVII, como vemos en este y en otros estudios.

Se puede pensar que escribió el texto en persa y luego, con la ayuda o intervención protagonista de fray Alonso Remón, lo convirtió al castellano. Hace en el mismo un listado de reyes persas que trufa de anécdotas sobre sus reinados, pero lo más destacado sería lo

\footnotetext{
33 Turley, T.S. \& Souza, G. B. The Commentaries of D. Garcia de Silva y Figueroa on his Embassy to Shah Abbās I of Persia on Behalf of Philip III, King of Spain.

34 Comentarios de la Embaxada al Rey Xa Abbas de Persia (1614-1624). Vols. 1 y 2. Edição de Rui Manuel Loureiro, Ana Cristina Costa Gomes \& Vasco Resende. Hay dos tomos más referidos al texto: Loureiro, R.M., Biedermann, Z. \& Nieto, McAvoy, E. (coordenação de) 2011, Anotações e Estudos sobre Don García de Silva y Figueroa e os "Comentários" da embaixada à Pérsia (1614-1624). Vol. 3, y Loureiro R. M. \& Resendo, V., 2011, Estudios sobre Don García de Silva y Figueroa e os "Comentarios" da embaixada à Pérsia (1614-1624). Vol. 4.

${ }^{35}$ Córdoba Zoilo, 2011-2012, "Viaje, hallazgos y fortuna de dos viajeros europeos del siglo XVII en Irán: García de Silva y Pietro del Valle".
} 
referente al siglo XVI, que narra o bien gracias a sus recuerdos y estudios, o bien a lo que le contó su padre, Ali Bec Bayat, personaje destacado de la corte. Nuestro personaje no se declara muy afín a Abbas I, y esto sin duda influyó en su deserción. Para contar la historia de Irán utilizan textos occidentales ${ }^{36}$ : la Monarquía Eclesiástica de fray Juan de Pineda, las Relaciones Universales de Juan Botero Banes, y la Historia de la guerra entre turcos y persianos de Juan Minadoi, lo cual, y don Juan no lo esconde, habla del papel que tuvo fray Alonso Remón en la obra, bien suministrando fuentes, bien haciendo de editor, bien escribiendo directamente.

Es, en cualquier caso, otro de los magníficos textos bibliófilos producto de estas embajadas, y una fuente de más o menos primera mano acerca del Irán del siglo XVII excepcional, aunque no única en la Europa contemporánea.

En los mismos años, desde el mismo ámbito, y no puede ser casualidad, se originan varios viajes por el mundo que son además publicados: sirvan como ejemplo los de Pedro Teixeira, Mendes Pinto, Ordoñez de Cevallos ${ }^{37}$ o Pedro Cubero ${ }^{38}$.

Las Relaciones de Pedro Teixeira d'el origen descendencia y succession de los Reyes de Persia, descendencia y succession de los Reyes de Persia, autor dende la India Oriental hasta Italia por tierra, publicadas en Amberes en 1610, es un texto especialmente interesante por ser la traslación de fuentes históricas contemporáneas iraníes sobre su historia, además de narrar otro magnífico viaje de la época.

La Peregrinaçao ${ }^{39}$ de Fernão Mendes Pinto (1511/14 - 1583) se publica en Lisboa en 1614, y casi de forma inmediata se traduce al español. Fue publicada póstumamente, se convirtió en una especie de best seller, y durante mucho tiempo se dudó de su veracidad, aunque luego esas dudas fueron despejadas. Parecía un periplo demasiado fantástico para ser cierto. El Viaje del mundo de Pedro Ordéñez de Cevallos fue publicado en Madrid en 1614, también. Más relacionado con América que con Asia, aunque también peregrinó a Jerusalén, es otro ejemplo de la cantidad y calidad de viajeros que desde la Corte Hispánica recorrieron el mundo y lo plasmaron en sus libros.

En 1680, en Madrid (Juan García Infançón), Pedro Cubero Sebastián publica su Breve relación de la peregrinación que ha hecho de la mayor parte del mundo Don Pedro Cubero Sebastian... con las cosas más singulares que le han sucedido y visto entre tan bárbaras naciones, su Religión, Ritos, Ceremonias y otras cosas memorables y curiosas que ha podido inquirir, con el viaje por tierra, desde España hasta las Indias Orientales, que cuenta con varias ediciones casi inmediatas y que es la última muestra que traemos aquí sobre esas peregrinaciones y viajes del mundo que se dieron en el siglo XVII, sin duda desde distintos puntos de partida, aunque parece que especialmente numerosos desde la Monarquía Hispánica que en ese momento gobernaba los imperios portugués, castellano y aragonés, estos ya unidos en una sola corona.

Estos viajes fueron objeto de narración y a veces de ensoñación, que dieron como resultados Comentarios, Relaciones u otros títulos que eran redactados para hablar del viaje realizado, de todo lo observado, y para profundizar en fuentes propias o locales (el punto de referencia utilizado varía) sobre la historia de Irán. Sorprende la cantidad de embajadas, pero sobre todo los textos que se dieron como resultado, entre la Monarquía Hispánica e Irán y también sorprende la calidad y excepcionalidad de alguno de ellos. Estos textos gozaron de la gloria del momento en algunos casos, o fueron prácticamente

\footnotetext{
36 Alonso Cortes, 1946, 13.

37 Libro de 1614: Ordoñez de Cevallos, P., Viage del Mundo hecho y compuesto por el Licenciado Pedro Ordoñez de Cavallos... y reeditado en 1993 por la editorial Miraguano.

38 Peregrinación del Mundo, 1682, Nápoles.

39 Peregrinaçam de Fernam Mendez Pinto. Em que da conta de muytas e muyto estranhas cousas que vio \& ouvio no reyno da China, no da Tartaria, no de Sornau...
} 
olvidados, recordados solo por algunos especialistas o editados de manos extranjeras en otros. Mucho tiempo después fueron rescatados del olvido por editores y estudiosos que quisieron sacarles del injusto olvido, o redescubiertos y mostrados en conjunto por estudiosos que tenían la misma pretensión ${ }^{40}$.

Cuando hablamos de los contactos a lo largo de la historia entre Irán y España, volvemos a estos grandes hitos y la sorpresa y la maravilla ante sus textos vuelven a surgir. De nuevo retornamos a profundizar y disfrutar con sus narraciones, del mismo modo que hace Adolfo Rivadeneyra cuando documenta y va presentando en su libro el viaje que piensa hacer. Cuando va introduciendo quienes le precedieron en su viaje a Irán.

\section{Epílogo y vuelta a Rivadeneyra}

El libro de Adolfo Rivadeneyra sobre su embajada en Irán, es fruto de la misión que le fue conferida por el Gobierno español, entre otras cosas para recopilar todo tipo de información que pudiese ser útil para el establecimiento de relaciones comerciales entre España y Persia, pero el autor fue mucho más allá. El libro incluye un variado abanico de información y noticias que pueden ser útil a un comerciante o viajero que quisiera trabajar o visitar Irán, y lo va contando según va recorriendo él el país. Pero nuestro vicecónsul es también un observador interesado, documentado, sabedor y con afán de aprender, de modo que a lo largo del recorrido se van tratando temas históricos, antropológicos, relacionados con el arte, con la arqueología, con un largo etcétera de ciencias que hoy distinguiríamos como diferentes. Formando, en resumen, un compendio de estudios y observaciones que trascurren paralelos al viaje que él mismo va haciendo por Irán.

El libro se publicó porque él estaba a cargo de la editorial de su padre, Manuel Rivadeneyra, junto a su cuñado, Joaquín Pi y Margall, y podía tomar esta decisión, porque de la promesa gubernamental de publicar su estudio nunca más se supo. Si no se hubiese dado esta circunstancia, esta posibilidad, no sabemos qué hubiese sido de este texto.

La recuperación o existencia de todos estos estudios únicos y sorprendentes en torno a los contactos entre España e Irán a lo largo de la historia que hemos ido repasando, se deben a veces a casualidades, o desconocemos los mecanismos o el porqué de su preservación. Su existencia, su conservación, es fruto sobre todo de la acción decidida de personas que decidieron escribirlos y luego conservarlos, estudiarlos y sacarlos a la luz, conscientes y sabedores de su importancia y de su valía. Esta misma labor se sigue desarrollando hoy en día, y así, el catálogo de publicaciones de textos olvidados y sacados a la luz de la editorial Miraguano ${ }^{41}$ es realmente impresionante, lo mismo que el trabajo académico llevado a cabo por el profesor Córdoba en la misma línea.

Esas son los caminos a seguir, continuar sacando a la luz y estudiando todos estos textos y embajadas que ya conocemos, trabajar con los que sabemos que existen pero aún no están adecuadamente divulgados y propiciar o estar atentos a los que hayan de aparecer. Queda mucho trabajo por hacer, es cierto, lo mismo que también es verdad que en estos veinte años se ha avanzado mucho, y debemos estar contentos por ello.

\section{Bibliografía}

Bec, Uruch / don Juan de Persia, 1604, Relaciones de don Juan de Persia. Dirigidas a la Magestad Catholica de don Philippe III. Rey de las Españas y señor nuestro. Divididas

\footnotetext{
40 En este sentido hay que señalar la exposición La Aventura Española en Oriente [1166-2006]. Viajeros, museos y estudiosos en la historia del redescubrimiento del Oriente Próximo Antiguo, celebrada en el Museo Arqueológico Nacional en 2006, comisionada por Joaquín M. Córdoba Zoilo y Carmen Pérez Die, así como el número 711-712 de Arbor, editado por Joaquín M. ${ }^{a}$ Córdoba: Españoles en Oriente Próximo (1166-1926). Aventureros y peregrinos, militares, cientificos y diplomáticos olvidados en el redescubrimiento de un mundo. ${ }^{41}$ http://www.miraguano-sa.es/
} 
en tres libros, donde se tratan las cosas notables de Persia, la genealogía de sus reyes, guerras de persianos, turcos y tártaros, y las que vido en el viaje que hizo a España: y su conversión, y la de otros dos caballeros persianos. En Valladolid, por Juan de Bostillo.

Beg, Uruch, 1946, Relaciones de don Juan de Persia. Prólogo y notas de Narciso Alonso Cortes. Madrid, Gráficas Ultra.

Córdoba Zoilo, J. Mª 1998, "Algunas notas sobre don García de Silva y el descubrimiento del Oriente a comienzos del siglo XVII", in J. Mangas \& J. Alvar (coord.) Homenaje a José María Blázquez, Vol. 1, págs. 353-362.

Córdoba Zoilo, J. Mª , 2001, «La percepción del Irán antiguo y contemporáneo en la obra de los viajeros españoles de los siglos XVII y XIX», in J. M. Córdoba, R. Jiménez Zamudio, C. Sevilla Cueva (eds.), El Redescubrimiento de Oriente Próximo y Egipto. Viajes, hallazgos e investigaciones. Universidad Autónoma de Madrid, Madrid, pp. 1-16.

Córdoba Zoilo, J. Ma , 2005, "Un caballero español en Isfahán. La embajada de Don García de Silva y Figueroa al sha Abbás el Grande (1614-1624)”, Arbor 711-712, págs. 645-669.

Córdoba Zoilo, J. Ma , 2006, “La época de los viajeros y el redescubrimiento: colores de Occidente y perfumes de Oriente: los viajeros hispanos de los Siglos de Oro: Don García de Silva y Figueroa, y el redescubrimiento de Irán", in Córdoba Zoilo J.M. y Pérez Díe, M.C (coord.), La aventura española en Oriente (1166-2006), Viajeros, museos y estudiosos en la historia del redescubrimiento del Oriente Próximo Antiguo, pp. 89-98.

Córdoba Zoilo, J. M" a 2011-2012, "Viaje, hallazgos y fortuna de dos viajeros europeos del siglo XVII en Irán. García de Silva y Pietro della Valle", Isimu: Revista sobre Oriente Próximo y Egipto en la antigüedad, Nº 14-15, (In Memoriam Donny George), págs. 165-218.

Córdoba Zoilo, J.M. y Pérez Díe, M.C. (coord.), 2006, La aventura española en Oriente (1166-2006). Viajeros, museos y estudiosos en la historia del redescubrimiento del Oriente Próximo Antiguo.

Cubero Sebastián, Pedro, 1993, Peregrinación del Mundo de Pedo Cubero Sebastián, Misionero apostólico. Biblioteca de Viajeros Hispánicos 10. Madrid, Miraguano Ediciones y Ediciones Polifemo.

Escribano Martín, F., 2015-16, “Aida, el Canal de Suez y su inauguración. Ópera en tres actos, epílogo y adenda", ISIMU 18-19, De Egipto y otras tierras lejanas, Covadonga Sevilla Cueva, In Memoriam, J. M ${ }^{\mathrm{a}}$ Córdoba, C. del Cerro y F.L. Borrego (coordinadores), pp. 291-302.

Escribano Martín, F., 2005, "El viaje del mundo de Pedro Ordoñez de Ceballos", Arbor 711-712, marzo-abril, pp. 581-594.

Escribano Martín, F., 2001, "Los estudios sobre Oriente en la España de finales del siglo XIX: la vida y la obra de Francisco García Ayuso", en J.M Córdoba Zoilo, R. Jiménez Zamudio, C. Sevilla Cueva (editores), Actas del Primer Seminario Monográfico de Primavera. El Redescubrimiento de Oriente Próximo y Egipoto. Viajes hallazgos e investigaciones, Madrid, UAM. Supplementa ad Isimu. II Series: Acta et Symposia Vol. I.

Fuente del Pilar, J.J., 2005, "Pedro Teixeira y su viaje por Mesopotamia", Arbor 711712, marzo-abril, pp. 627-643.

Gil Fernández, L., 2006 y 2009, El Imperio luso-español y la Persia safávida. Tomo I (2007) (1582-1605) y tomo II (2009) (1606-1622). Fundación Universitaria Española, Madrid.

González de Clavijo, R., 1582, Historia del Gran Tamorlán e Itinerario y Enarración del viaje, y relación de la Embaxada que Ruy González de Clavijo le hizo por mandado del muy poderoso Señor Rey Don Henrique el Tercero de Castilla, y un breve discurso fecho por Gonçalo Argote de Molina, para mayor inteligencia deste libro. Dirigido al 
muy Illustre Señor Antonio Pérez, del consejo de su Magestad, y su Secretario de Estado. Sevilla, casa de Andrea Pescioni, año de MDLXXXII.

González de Clavijo, R., 1782, Mismo título que la edición previa, más: Segunda impresión, a que se ha añadido la Vida del Gran Tamorlán sacada de los comentarios, que escribió don García de Silva y Figueroa, de su embajada al Rey de Persia. En Madrid. En la Imprenta de don Antonio de Sancha, año de MDCCLXXXII. [Eugenio de Llaguno Amírola cuidó de la edición y puede ser el responsable de parte de la introducción.]

González de Clavijo, R., 1943, Embajada a Tamorlán, estudio y edición de un manuscrito del siglo XV por Francisco López Estrada. Madrid, CSIC.

González de Clavijo, R., 1984, Embajada a Tamorlán. Cuadernillo introductorio a cargo de Ramón Alba. Madrid, Miraguano Ediciones.

López Estrada, F., 2005, "Ruy González de Clavijo. La embajada a Tamorlán. Relato del viaje hasta Samarcanda y regreso (1403-1406)", Arbor 711-712, Españoles en Oriente Próximo (1166-1926). Aventureros y peregrinos, militares, científicos y diplomáticos olvidados en el redescubrimiento de un Mundo. Joaquín M. ${ }^{a}$ Córdoba (Editor).

Loureiro, R.M., Biedermann, Z. \& Nieto, McAvoy, E. (coordenação de) 2011, Anotações e Estudos sobre Don García de Silva y Figueroa e os "Comentários" da embaixada à Pérsia (1614-1624). Vol. 3. Centro de História de Além-Mar. Lisboa.

Loureiro R. M. \& Resendo, V., 2011, Estudios sobre Don García de Silva y Figueroa e os "Comentarios" da embaixada à Pérsia (1614-1624). Vol. 4. Centro de Historia de Além-Mar. Lisboa.

Mendes Pinto, Fernao, 1614, Peregrinaçam de Fernam Mendez Pinto. Em que da conta de muytas e muyto estranhas cousas que vio \& ouvio no reyno da China, no da Tartaria, no de Sornau, que vulgarmente se chama Sião, no de Calaminhan, no de Pegú, no de Martavo, \& em outros muytos reynos \& senhorios das partes Orientais, de que nestas nossas do Occidente ha muyto pouca ou nenhuma notícia. E tambem da conta de muytos casos particulares que acontecerão assi a elle como a muytas pessoas. E no fim della brevemente de alguas cousas, \& da morte do Santo Padre mestre Francisco Xavier, unica luz \& resplandor daquellas partes do Oriente, \& Reytornellas universal da Companhia de Iesus. Escrita pelo mesmo Fernão Mendez Pinto. Dirigido à Catholica Real Magestade del Rey dom Felippe o II deste nome nosso Senhor. Com licença do Santo Officio, Ordinario \& Paço. Em Lisboa. Por Pedro Crasbeeck. Anno 1614. A custa de Belchior de Faria Cavaleyro da casa del Rey nosso Senhor, \& seu livreyro. Com privilegio Real.

Traducido en 1620 al español: En Madrid, por Tomas Iunti, Impressor del Rey nuestro Señor./ Impressa a costa de Manuel Rodriguez, Mercader de Libros.

Ordoñez de Cevallos, P., 1614, Viage del Mundo hecho y compuesto por el Licenciado Pedro Ordoñez de Cavallos, natural de la insigne ciudad de Iaen. Contiene tres libros. Dirigido a Don Antonio Davila y Toledo, sucesor y mayorazgo en la casa de Velada. Con Privilegio, por Luis Sanchez, impressor del Rey N.S. Año M.DC.XIIII.

Ordoñez de Ceballos, P., 1993, Viaje del Mundo. Biblioteca de Viajeros Hispánicos, 8. Miraguano Ediciones \& Ediciones Polifemo. Madrid.

Santiño, Santiago. Pascual de Gayangos. Erudición y cosmopolitismo en la España del XIX. Urgoiti editores, Pamplona, 2018.

Sherley, A., 1613, His relation of his travels into Persia : the dangers, and distresses, which befell him in his passage, both by sea and land, and his strange and vnexpected deliuerances : his magnificent entertainement in Persia, his honourable imployment therehence, as embassadour to the princes of Christendome, the cause of his disapointment therein, with his aduice to his brother, Sir Robert Sherley: also, a true relation of the great magnificence, valour, prudence, iustice, temperance, and other manifold vertues of Abas, 
now King of Persia, with his great conquests, whereby he hath inlarged his dominions. London. Printed for Nathaniell butter, and Iosepht Bagset.

Sherley, A., 1961, Peso político de todo el mundo del Conde D. Antonio Xerley. Edición de Carmelo Viñas y Mey. Departamento de Historia Social. Instituto "Balmes" de Sociología. CSIC, Madrid.

Sherley, A., 2010, Peso de todo el mundo (1622) y Discurso sobre el aumento de esta monarquía (1625). Ed y estudios de Ángel Alloza Aparicio, Miguel Ángel de Bunes y José Antonio Rodríguez Torres. Madrid, Ediciones Polifemo.

Silva y Figueroa, G. de, 1618 (cronología de la BN), Comentarios de don García de Silva que contienen su viaje a la India y de ella a Persia, cosas notables que vió en él y los sucesos de la embajada al Sophi [Manuscrito].

Silva y Figueroa, G., 1667. L'ambassade de Garcias de Silua Figueroa en Perse: contenant la politique de ce grand empire, les moeurs du Roy Schach Abbas, \& vne Relation exacte de tous les lieux de Perse \& des Indes, oú cét Ambassadeur a esté l'espace de huit années qu'il y a demeurè. Traduit de l'espagnol par Monsier de Wicqfort. París, chez Iean du Puis.

Silva y Figueroa, G. de, 1903 y 1905, Comentarios de D. García de Silva y Figueroa de la Embajada que de parte del rey de España Don Felipe III hizo al rey Xa Abas de Persia. Madrid: Sociedad de Bibliófilos Españoles. Edición de Manuel Serrano y Sanz.

Silva y Figueroa, G. de, 1989, Epistolario diplomático. Edición y estudios preliminares de Luis Gil. Institución Cultural "El Broncense", Cáceres.

Silva y Figueroa, G. de, 2011, Comentarios de la Embaxada al Rey Xa Abbas de Persia (1614-1624). Vols. 1 y 2. Edição de Rui Manuel Loureiro, Ana Cristina Costa Gomes \& Vasco Resende. Centro de História de Além-Mar. Universidade Nova de Lisboa, Universidade dos Açores. Lisboa 2011.

Silva y Figueroa, G. de, 2017. The Commentaries of D. Garcia de Silva y Figueroa on his Embassy to Shah Abbās I of Persia on Behalf of Philip III, King of Spain. Brill, Leiden/Boston.

Villalón, Cristobal de, 1973. Viaje de Turquía. Círculo de Amigos de la Historia. Editions Ferni, Genève.

Teixeira, P., 1994, Relaciones de Pedro Teixeira del origen, descendencia y succession de los reyes de Persia, y de Harmuz, y de un viaje hecho por el mismo autor dende la India Oriental hasta Italia por Tierra. Biblioteca de Viajeros Hispánicos 12. Miraguano Ediciones \& Ediciones Polifemo. Madrid. (Edición original publicada en Amberes en 1610).

Turley, T.S. \& Souza, G. B., 2017, The Commentaries of D. Garcia de Silva y Figueroa on his Embassy to Shah Abbās I of Persia on Behalf of Philip III, King of Spain. Brill, Leiden/Boston. 